PSICOLOGIA

IBEROAMERICANA
Psicología Iberoamericana ISSN: 1405-0943

revista.psicologia@ibero.mx

Universidad Iberoamericana, Ciudad de México México

\title{
La identidad imposible: algunos apuntes sobre 'el doble' en Borges y en el psicoanálisis
}

Vara Miranda, Eliab Ammissaday

La identidad imposible: algunos apuntes sobre 'el doble' en Borges y en el psicoanálisis

Psicología Iberoamericana, vol. 28, núm. 2, 2020

Universidad Iberoamericana, Ciudad de México, México

Disponible en: http://www.redalyc.org/articulo.oa?id=133964928005

Esta obra está bajo una Licencia Creative Commons Atribución 4.0 Internacional.

Esta obra está bajo una Licencia Creative Commons Atribución 4.0 Internacional.

\section{(c) (1)}

Esta obra está bajo una Licencia Creative Commons Atribución 4.0 Internacional. 


\title{
La identidad imposible: algunos apuntes sobre 'el doble' en Borges y en el psicoanálisis
}

\author{
The impossible identity: Some notes on the 'double' in Borges \\ and in psychoanalysis \\ Eliab Ammissaday Vara Miranda eliab_vm@hotmail.com \\ Universidad Autónoma del Estado de México, México \\ http://orcid.org/0000-0001-5407-5719
}

Psicología Iberoamericana, vol. 28, núm. 2,2020

Universidad Iberoamericana, Ciudad de México, México

Recepción: 18 Mayo 2020 Aprobación: 27 Agosto 2020

Redalyc: http://www.redalyc.org/ articulo.oa?id=133964928005
Resumen: El artículo cuestiona la noción de identidad a través de un estudio del doble tanto en la teoría psicoanalítica como en algunos textos de la obra de Jorge Luis Borges. En el documento se hace una reseña de lo que el psicoanálisis entiende por identidad, así como su conceptualización del doble. A partir de allí, se utilizan elementos de esta teoría sobre el tema, específicamente los espejos, lo ominoso y, sobre todo, el Otro, para analizarlos dentro de ciertos textos representativos del escritor argentino, lo cual sugiere que hay una convergencia entre ambas perspectivas con respecto a la imposibilidad de la identidad.

Palabras clave: Borges, psicoanálisis, identidad, doble, otro.

Abstract: The article questions the notion of identity through a study of 'the double' both in psychoanalytic theory and the work of Jorge Luis Borges. In the article, an argument is made of what psychoanalysis understands by identity, as well as its conceptualization of 'the double'. From there, elements of this theory on the subject are applied, specifically the mirrors, the ominous and, above all, the Other, in order to analyze them within the texts of the Argentine writer, Borges. This suggests that there is a convergence between both perspectives regarding the impossibility of identity.

Keywords: Borges, psychoanalysis, identity, double, other.

\section{Introducción}

El objetivo de este artículo es explorar la imposibilidad del concepto de identidad en el psicoanálisis y en la obra de Jorge Luis Borges, a través del tema del doble. Serán tomados en consideración los postulados de Freud y Lacan con respecto a dichas cuestiones, así como algunos textos representativos del autor de El Aleph que, sorprendentemente, tienden más a la similitud que a la diferencia con respecto a las teorizaciones psicoanalíticas.

El cuestionamiento de Borges acerca del concepto de identidad es conocido debido a la insistencia con la que lo ensayó a lo largo de su obra. Esta singularidad puede ser estudiada desde un sinfín de perspectivas (que se multiplican descomunalmente, tratándose de la literatura del escritor argentino), pero encuentra un vínculo especial con la teoría psicoanalítica, en tanto ésta se funda a partir del mismo interrogante.

El psicoanálisis freudiano postuló casi desde sus inicios la existencia de fuerzas contiguas a la razón, con lo cual ayudó a desmantelar el edificio que ésta había construido durante varios siglos. Descubrimientos como 
el del inconsciente o las instancias psíquicas suscitaron una controversia con respecto a la posibilidad de seguir sustentando la idea de la identidad; controversia a la que Lacan brindó, a su vez, argumentos notables sobre la formación del yo.

Por el lado de la literatura borgesiana, los recursos de los que el autor hizo uso para interpelar la identidad son diversos (Huici, 1994). Desde el panteísmo en narraciones como "El inmortal" o "El acercamiento a Almotasim", en las que los personajes se funden en uno solo; hasta el idealismo filosófico sobre el que se sustentan tanto "Las ruinas circulares" -que se comentará más adelante-como la "Nueva refutación del tiempo", en la que Borges discutió la dificultad de preservar conceptos como la materia, el tiempo o la identidad.

Sin embargo, uno de los temas predilectos que permitieron al escritor poner en entredicho a esta última fue, previsiblemente, el del doble ${ }^{[1]}$. Esto sucede no sólo en la célebre tríada de textos en los que el personaje "Borges" tiene encuentros consigo mismo ("Borges y yo", "El otro" y "25 de agosto, 1983"), sino en toda la obra del autor, cuya cantidad de ejemplos en los que aparece un doble lo convierten en un leitmotiv.

Esto resulta muy pertinente en un estudio que pretende encontrar paralelismos sobre el concepto de identidad -o la falta de éstaentre la obra borgesiana y el psicoanálisis puesto que, aunque parten de fundamentos distintos, específicamente el tema del doble provee elementos en los que ambas posturas convergen.

Dichas convergencias, claro está, ya han sido estudiadas previamente. Como ejemplos significativos se encuentran el estudio de Woscoboinik (1988), en el que se indagan diversos temas psicoanalíticos en la obra del argentino, haciendo una mención del rol angustiante de los espejos en sus pesadillas. Este punto es retomado por Braunstein (2008), quien lo asocia con los recuerdos infantiles de Borges para analizar las consecuencias que éstos tienen en su escritura, en su identidad y hasta en su ceguera.

Si se delimita aún más la confluencia para enfocarse directamente en el doble borgesiano y el psicoanálisis, es posible encontrar artículos de relevancia, que además fueron tomados en consideración para la elaboración de este texto. Del lado de la literatura se encuentra el estudio de Huici (1994), que apunta numerosas ideas sobre la función del doble en la obra de Borges, reconociendo el vínculo de algunas con la teoría psicoanalítica. Del lado del psicoanálisis, Lobo (2010), repasa varias ideas que la literatura, la psiquiatría clásica, Freud y Lacan han establecido con respecto al doble, si bien no lo enlaza directamente con la obra de Borges. En ese sentido, el artículo de Muñoz (2013) es el más cercano a lo que pretende este estudio, pues parte de un análisis de ciertos textos borgesianos para elaborar análisis muy precisos sobre el doble en Freud y Lacan, los cuales fueron muy útiles para el desarrollo de este escrito.

$\mathrm{Al}$ respecto, es importante señalar que este último se enmarca en los desarrollos ya planteados, sobre todo por Huici y Muñoz. El objetivo es enriquecer dichas perspectivas, partiendo de los elementos psicoanalíticos que usualmente se vinculan al doble, pero dando un espacio mayor al concepto del Otro, que en la obra de Borges lleva a conclusiones que no 
han sido señaladas en estos términos. A la vez, se busca apuntar a ciertos escritos borgesianos que tratan el doble, aunque no es su tema principal, por lo que no se han abordado tanto en los análisis acerca de éste.

Para dirigirse hacia dichos objetivos, el documento se divide en tres apartados. En primer lugar, se revisarán, a grandes rasgos, los postulados psicoanalíticos que comprenden el cuestionamiento hacia la identidad. El segundo apartado se enfoca también en el psicoanálisis, y versa sobre el estudio del doble desde esta teoría. Para terminar, este documento se concentrará en ciertos elementos relacionados con el doble para analizar algunos textos representativos de Borges y, de este modo, ir tejiendo vínculos entre las dos obras seleccionadas.

\section{El Cuestionamiento de la Identidad Desde el Psicoanálisis}

La idea de un estrato inconsciente de la personalidad ya se venía sugiriendo por el romanticismo y la filosofía, pero fue Freud quien vino a sistematizarla. En "Lo inconsciente" (Freud, 1915 [2010]), el psicoanalista vienés sintetiza sus ideas con respecto a su primera tópica y señala la existencia de un sistema inconsciente que no sólo tiene propiedades diferentes al preconsciente-consciente, sino que influye en éste a través de la energía de sus representaciones reprimidas. De este modo, no se puede hablar de un aparato indivisible, sino de uno en el que diferentes sistemas interactúan entre sí.

Más aún, en "El yo y el ello", Freud (1923 [2010]) precisa que, además de los sistemas de su primera tópica, existen tres instancias que conforman al aparato psíquico: el ello, el yo y el superyó. En este texto describe las relaciones nada tersas entre estas instancias que dependen del desarrollo infantil y responden cada una a su propia lógica. Freud concluye que aquella instancia que podría vincularse con la identidad, el yo, no es completamente consciente y no puede lograr lo que pretende: mediar todo el sistema. Lo anterior debido a que tiene que lidiar continuamente con las pulsiones del ello, la severidad del superyó y las exigencias del mundo exterior. Lo que el autor enseña es que las ideas de consciencia e identidad son inconcebibles, dado que hay otros sistemas e instancias que apuntan más bien a un sujeto dividido.

A esto se añade que la misma formación del yo encuentra una serie de escollos que será pertinente revisar, desde la teoría lacaniana. En "El estadio del espejo como formador de la función del yo (je) tal como se nos revela en la experiencia psicoanalítica" (Lacan, 2009), se menciona que durante el estadio del espejo, el sujeto en ciernes comienza por percibir una imagen fragmentada de su cuerpo, pero más adelante se va identificando con una forma más unificada de sí mismo.

Esto sucede gracias a la intervención del Otro, el cual es un concepto recurrente en la teoría de Lacan, si bien su concepción se va modificando a lo largo de su obra. En ese sentido, se revisarán las características que encuentren una relación con el desarrollo del yo ${ }^{[2]}$, ya que también serán de utilidad para el análisis ulterior. Para empezar, hay que decir que el psicoanalista francés (Lacan, 1955 [2006]) menciona que al escribirlo con 
mayúscula está haciendo alusión no a un compañero imaginario, sino que lo identifica como un lugar particular, el de la constitución de sujeto. Este lugar es el del origen del significante (Lacan, 1957 [2006]), el espacio de la alteridad del lenguaje que precede al sujeto y que éste encuentra desde su entrada al mundo, de lo cual se concluye que el Otro es tanto anterior como exterior a aquél.

Debido a que el lenguaje viene al sujeto a través del Otro es que éste es también el lugar de su constitución, como recién se mencionó. Esta operación se lleva a cabo a través de aquellos que acogen al recién nacido -usualmente sus padres- lo que ha llevado a la tendencia de identificar al Otro con la madre, sin que esto signifique que sean sinónimos. Sin embargo, es cierto que el infante depende tanto de su madre, que toma de ella referentes para constituirse, como su nombre y su imagen.

El sujeto recibe la imagen unificada de su cuerpo en el espejo como un don del Otro, quien además le habla y lo nombra, con lo cual aquél va conformando a su yo. Sin embargo, hay que recalcar que siempre hay una distancia entre esta imagen yoica y el propio sujeto quien - como se mencionó previamente-, está dividido. Debido a que los referentes son insuficientes, a que el nombre y la imagen no pueden aprehender todo el ser del sujeto, siempre queda una falta.

La existencia de una falta también aplica con respecto al Otro. El hecho de que se conceptualice como el lugar de la constitución del sujeto parecería dotarlo de un dominio sobre éste. Sin embargo, Lacan (1973 [2006]) va a insistir en que el Otro está barrado, lo cual significa que no hay en realidad una garantía de su verdad y, por lo tanto, su determinación sobre el sujeto es sólo parcial. Así, la teoría lacaniana indica una falta que atraviesa tanto al sujeto como al Otro, con lo cual muestra también la imposibilidad de arribar a un concepto de identidad.

Empero, en todas estas elaboraciones hay elementos importantes que serán de utilidad más adelante y que es oportuno resaltar pues apuntan a un mismo destino: la alteridad. Por un lado, está el espejo, objeto que le devuelve al sujeto la imagen de otro idéntico a sí mismo. Esto no es menor, dado que no es realmente una correspondencia, sino el origen de una brecha que no terminará nunca de cerrarse entre el ser y su representación que ya es, en sí misma, un segundo yo, mismo que no termina de aprehender al primero.

Asimismo, está esa profunda alteridad que es el Otro, enigmático lugar que tiene injerencia en el destino del sujeto puesto que de allí provienen su nombre y el don de su imagen, delicados pilares de un yo que siempre está en entredicho. Todo esto apunta, por supuesto, al interrogante por la identidad, que se intensifica al tocar los terrenos del doble. Será necesario transitarlos entonces, comenzando por la postura del psicoanálisis para arribar a su desarrollo en la obra de Borges.

\section{El Doble en el Psicoanálisis}

Es fácil anticipar que las mencionadas formas de la alteridad, el espejo y el Otro, llevan directamente al tema del doble, visto desde el psicoanálisis. 
De esta manera, no será un desacierto citar el artículo que es clave para la comprensión de éste: "Lo ominoso" (Freud, 1919 [2010]). Como es bien sabido, en este breve texto se analizan algunos fenómenos que provocan la sensación de lo unheimlich, que se define como aquello familiar que, debiendo permanecer oculto, sale a la luz y produce un efecto particularmente angustiante.

De entre estos fenómenos, el del doble recibe una atención peculiar por parte de Freud, quien ensaya algunas hipótesis acerca de los motivos que lo vuelven ominoso. Primero señala los estudios de Rank al respecto, quien ya había lo había relacionado tanto con la sombra como con el espejo. A partir de allí, Freud especifica que originalmente el doble es un aseguramiento frente a la muerte que proviene del narcisismo primario, en la medida en que aquél puede perpetuar la vida del sujeto. De allí que señale que la figura del alma debe ser uno de los primeros dobles en el imaginario de la humanidad.

Sin embargo, ya superada la etapa del narcisismo primario, el doble cambia de signo y se vuelve un ominoso anunciador de la muerte. Freud comienza explicando lo anterior en términos de una proyección de yo sobre el doble, pero le parece insuficiente. Al final, se queda con la hipótesis de que lo que vuelve siniestro al doble es que, como recién se vio, éste es una formación psíquica primitiva del desarrollo del yo, de la etapa en que éste aún no se encuentra separado del mundo exterior y del otro. En síntesis, es algo familiar que debió permanecer oculto y aparece de pronto, sobre todo en producciones artísticas, como la literatura.

Si a esta proposición se le añade lo que ya se revisó con respecto a la formación del yo, de acuerdo con la teoría lacaniana, es fácil concluir que el núcleo familiar de aquello que se convertirá en lo ominoso se encuentra en el período del estadio del espejo. He aquí la partícula que permanecerá oculta hasta que algún encuentro infortunado con el doble la saque a la luz. "Los desarrollos de Lacan sobre el estadio del espejo nos aclaran el origen del sentimiento de lo siniestro: la imagen del niño en el espejo que sirvió para sostenerlo y unificarlo, retorna desde fuera amenazando su integridad" (Muñoz, 2013, p. 89).

¿Por qué es angustiante que, de súbito, el doble le devuelva al sujeto, como un espejo, elementos de la constitución de su yo? Quizá porque le recuerda que lo que cree es su identidad se asienta sobre una base endeble, que antes fuese la extraña percepción de un cuerpo fragmentado. O será que le muestra la brecha insalvable entre él y su imagen, que nunca ha sido verdaderamente suya pues le fue asignada, así como su nombre, por una terrible alteridad. Empero, la identidad del sujeto tampoco le pertenece a ese Otro quien, en última instancia, comparte la misma carencia, de tal modo que el sujeto se queda sin asideros que le aseguren ya no sólo su identidad, sino su existencia misma. Será interesante analizar cómo se conjugan estos elementos en la obra borgesiana, en la que el doble tiene un lugar harto significativo. 


\section{El Doble y el Otro en Borges}

Regresando a la literatura de Borges, se podrá notar que el uso del doble se dirige hacia los mismos interrogantes sobre la identidad, como bien lo sintetiza Huici, en el artículo antes mencionado:

«El doble», tal como Borges lo presenta en muchos de sus mejores cuentos, pero también en su poesía y en sus ensayos, se erige como interrogación permanente. Interrogación que, en primera instancia, puede plantearse del modo más simple, bajo la forma: ¿Quiénes somos?, pero que luego se irá precisando -y complicando- para pasar a ¿̇omos quienes realmente creemos ser? Hasta llegar al radical escepticismo de la última pregunta: ¿Somos? (Huici, 1994, p. 251).

Hasta aquí es más que claro el cuestionamiento, casi demolición, que ambas perspectivas, la psicoanalítica y la borgesiana, han hecho con respecto a la identidad. También es visible que el doble es, ciertamente, un fenómeno crucial para esa operación ${ }^{[3]}$. Es tiempo de enfocarse en los recursos que Borges utiliza, en algunos de los textos que abordan el tema del doble, para interpelar la identidad y que, sorprendentemente, encuentran un vínculo muy íntimo con aquellos ya mencionados en el psicoanálisis; a saber: los espejos, lo ominoso y, sobre todo, el Otro.

Como lo señalan otros estudios ${ }^{[4]}$, los espejos en la obra de Borges tienen un matiz realmente angustiante, lo cual se comprueba una y otra vez en su obra. Los espejos acechan, como en el inicio de "Tlön, Uqbar, Orbis Tertius", o en el poema "Insomnio"[5]. Este carácter ominoso también se le puede aplicar al doble, como recuerda Huici (1994, pp. 252-253) con respecto al "Poema de los dones". En éste, el autor es quien se coloca como el doble del escritor Paul Groussac, quien perdiese la vista al dirigir la misma Biblioteca. Escribe Borges (2005b) en OCII: “Al errar por las lentas galerías/suelo sentir con vago horror sagrado/que soy el otro, el muerto, que habrá dado/los mismos pasos en los mismos días" (p. 199). El horror que percibe el poeta es otro nombre de lo ominoso.

Este sentimiento aplica entonces tanto al doble como a los espejos, recursos que, a decir verdad, es imposible separar dentro de la literatura borgesiana. Un claro ejemplo de ello es el poema "El espejo", en el que se mencionan todos estos elementos: "Yo que sentí el horror de los espejos/ no sólo ante el cristal impenetrable/donde acaba y empieza, inhabitable, / un imposible espacio de reflejos" (Borges, 2005b, p. 204). Y más adelante: "Nos acecha el cristal. Si entre las cuatro/paredes de la alcoba hay un espejo, /ya no estoy solo. Hay otro. Hay el reflejo/que arma en el alba un sigiloso teatro" (Borges, 2005b, p. 205). Cada vez que un espejo es presentado en la obra de Borges, es sinónimo de la presencia de un doble vigilante que acecha y que presagia el posterior sentimiento de lo ominoso ${ }^{[6]}$. En el clásico estudio de Barrenechea, La expresión de la irrealidad en la obra de Borges, la autora lo describe minuciosamente:

El espejo guarda en su reflejo empañado una constante sugestión de irrealidad y de poesía que suele enriquecerse, como ya indicamos, con alusiones a los arquetipos platónicos, a la creencia popular en el doble 
y en los espejos mágicos, a la idea gnóstica de que el universo es una copia invertida del orden celeste, a la deformación monstruosa o a la multiplicación infinita de sus superficies enfrentadas. Pero insinúe o no cualquiera de estos aspectos, siempre basta su sola presencia para sentir la disolución que nos amenaza (Barrenechea, 1984, p. 98).

Esto se lleva hasta sus últimas consecuencias en "Los espejos velados. El texto comienza con una confesión en la que el autor se extiende en los motivos por los cuales un espejo podría ser ominoso. A la vez, se relaciona de manera íntima con lo mencionado acerca del estadio del espejo lacaniano:

Yo conocí de chico ese horror de una duplicación o multiplicación espectral de la realidad, pero ante los grandes espejos. Su infalible y continuo funcionamiento, su persecución de mis actos, su pantomima cósmica, eran sobrenaturales entonces, desde que anochecía. Uno de mis insistidos ruegos a Dios y al ángel de mi guarda era el de no soñar con espejos. Yo sé que los vigilaba con inquietud. Temí, unas veces, que empezaran a divergir de la realidad; otras, ver desfigurado en ellos mi rostro por adversidades extrañas (Borges, 2005b, p. 174).

Como puede notarse en esta cita, el encuentro del niño con su reflejo no es totalmente armonioso y, en última instancia, siempre incluye el conflicto que se ha descrito con respecto a la identidad, si bien en el caso de Borges, éste adquiere variaciones sobrecogedoras. Volviendo al texto, más adelante el narrador comparte estas inquietudes con una amiga: "Es común referir a las mujeres, para intimar con ellas, rasgos verdaderos o apócrifos del pasado pueril; yo debí contarle una vez de los espejos y dicté asi [las cursivas son mías], el 1928, una alucinación que iba a florecer el 1931." (Borges, 2005b, p. 174).

De acuerdo con lo señalado el narrador "dicta" esta ulterior alucinación, exhibiéndose después como quien posee la imagen que usurpa la de su amiga y que habrá de perseguirla, como los dobles acechantes sobre los cuales se ha hecho alusión: "Ahora, acabo de saber que se ha enloquecido y que en su dormitorio los espejos están velados pues en ellos ve mi reflejo, usurpando el suyo, y tiembla y calla y dice que yo la persigo mágicamente" (Borges, 2005b, p. 174). De todo esto se desprende que el narrador es aquí no sólo la alteridad que está representada en el doble, sino quizá también el Otro, en los términos que se han trabajado con anterioridad, en tanto influye en el futuro de su amiga y le asigna a su vez una imagen, lo cual termina por enloquecerla.

Este juego de dominio ha sido una constante en buena parte de la literatura que aborda el tema del doble. En su ilustrativo estudio al respecto, Bargalló (1994) expone numerosos ejemplos en los que sucede esta dinámica y, al hacer alusión a "Le Horla", de Maupassant, apunta lo siguiente: "El narrador está convencido de que en cada hombre hay dos seres: uno, el visible, y otro, el invisible que se erige en dominador del primero" (Bargalló, 1994, p. 21). Este segundo ser recuerda tanto al inconsciente ${ }^{[7]} \mathrm{y}$ su influencia sobre la vida del sujeto, tal y como se expuso previamente. A la vez, se aproxima a lo que se ha dicho acerca del Otro ${ }^{[8]}$, tanto desde el psicoanálisis como en "Los espejos velados". 
En el escritor argentino estas dinámicas de dominio puestas en el recurso del doble aparecen con mucha claridad en textos tan citados como "Borges y yo" ${ }^{[9]}$. Empero, aunque se trata de un reflejo de éste, es el poema "El centinela" el que está cargado de referencias a un doble mucho más dominante (y hacia el cual se mantiene una relación de mayor hostilidad). A riesgo de saturar este escrito, se transcribe el poema completo, debido a la claridad con que exhibe la relación de dominio del doble con respecto al sujeto:

Entra la luz y me recuerdo; ahí está. /Empieza por decirme su nombre, que es (ya se entiende) el mío. /Vuelvo a la esclavitud que ha durado más de siete veces diez años. / Me impone su memoria. / Me impone las miserias de cada día, la condición humana. /Soy su viejo enfermero; me obliga a que le lave los pies. / Me acecha en los espejos, en la caoba, en los cristales de las tiendas. /Una u otra mujer lo ha rechazado y debo compartir su congoja. / Me dicta ahora este poema, que no me gusta. /Me exige el nebuloso aprendizaje del terco anglosajón. /Me ha convertido al culto idolátrico de militares muertos, / con los que acaso no podría cambiar una sola palabra. /En el último tramo de la escalera siento que está a mi lado. / Está en mis pasos, en mi voz. /Minuciosamente lo odio. /Advierto con fruición que casi no ve. /Estoy en una celda circular y el infinito muro se estrecha. /Ninguno de los dos engaña al otro, pero los dos mentimos. / Nos conocemos demasiado, inseparable hermano. /Bebes el agua de mi copa y devoras mi pan. / La puerta del suicida está abierta, pero los teólogos afirman que en/la sombra ulterior del otro reino, estaré yo, esperándome (Borges, 2005b, p. 524).

Basta con prestar atención a los verbos que usa el sujeto al intentar describir lo que el doble hace de él ("me impone", "me obliga", "me acecha", "me dicta", "me exige") para corroborar el tipo de relación que mantienen. Y aunque el texto sugiere, a su vez, un testimonio patético de la senectud, el doble descrito acecha, a pesar de su ceguera; y sin importar que ya lleva décadas haciéndolo, miente, devora y esclaviza. Es un doble ominoso, en tanto exhibe algo que puede resultar familiar y, sin embargo, debería permanecer oculto: la dependencia frente al Otro, tal y como el psicoanálisis muestra que se vive la infancia, especialmente en la época del estadio del espejo.

Cabe preguntarse, entonces, si lo siniestro del doble no es sólo el hecho de que saque a la luz lo concerniente a la formación del yo, como especifica Freud, ni que recuerde la experiencia de depender del Otro, como se vive en el estadio del espejo lacaniano, sino también la posibilidad de que este doble comparta, asimismo, características del Otro. En "Los espejos velados", como se dijo antes, el narrador es el doble de su amiga, pero además le fija una imagen en el espejo y dicta su alucinación ulterior. En "El centinela", el doble brinda un nombre, impone recuerdos y, más aún, la propia condición humana. En ese sentido, estos dobles son ominosos porque llevan consigo las marcas de una época que debió quedar reprimida, pero, sobre todo, pareciera que poseen características que usualmente se le atribuyen al Otro: el ser el lugar de donde el infante toma 
su nombre y su imagen como un don, el lugar de la constitución del sujeto, en el que éste accede al leguaje, sostén de la condición humana.

Es importante aclarar que no se pretende asimilar al doble completamente con el Otro, pues se reconoce que hay muchos rasgos de ambos que no coinciden, pero si se acepta esta propuesta, es posible analizar un par de textos de Borges a la luz de dicha convergencia, que parece manifestarse en ciertas figuras. Por ejemplo, en la idea borgesiana del creador confluye tanto el concepto del Otro, como aquel personaje divino que conforma la vida de sus invenciones, como el recurso del doble, ya que aquél es parte de una serie de reflejos especulares que se extiende al infinito.

Lo anterior puede irse observando en "Las ruinas circulares", narración en la que el personaje de un mago comienza siendo una entidad suprema con la capacidad de concederle la vida a un hombre onírico. A la manera de un Otro paternal, este personaje lo va conformando a su imagen y en múltiples ocasiones lo denomina su hijo. Mientras avanza el relato se percibe la preocupación de este padre por la posibilidad de que su creación note que es sólo un simulacro. En el conocido final, el creador se entera que él mismo no es más que un sueño ${ }^{[10]}$, lo cual lleva al lector a pensar cuántos soñadores más (incluido él mismo) comparten ese destino ominoso.

En este cuento, el mago puede considerarse un doble en tanto repite el destino de su creación de no ser más que un sueño, lo cual genera una puesta en abismo. A la vez, tiene características del Otro, puesto que el hombre onírico toma de él lo necesario para constituirse. En un tenor muy similar, en "El Golem", Borges ofrece la historia del rabino de Praga quien, "sediento" de la sabiduría divina, crea y da vida a un muñeco, el Golem que replica con torpeza las formas de un ser humano, pero no alcanza a configurar un lenguaje. Al fijarse en él, en sus ojos, menos de perro que de cosa, el rabino siente horror y se pregunta por el desdichado momento en que decidió crearle. "En la hora de angustia y de luz vaga, / en su Golem los ojos detenían. / ¿Quién nos dirá las cosas que sentía / Dios, al mirar a su rabino en Praga?" (Borges, 2005b, p. 281).

Las semejanzas entre estos dos escritos han sido señaladas por el propio Borges en el prólogo de El otro, el mismo (Borges, 2005b, p. 251) aunque, a diferencia del cuento, en el que sólo el mago llega a la anagnórisis de saberse ficticio, en el caso del poema, el escritor lleva su interrogante a un nivel divino, para reafirmar que su juego de dobles reflejados unos frente a otros podría seguir indefinidamente ${ }^{[11]}$. De esta manera, se alcanza la esfera de lo divino, en la que no parecen existir tantas diferencias con respecto a la meramente humana.

Uno de los mejores ejemplos de lo anterior, el Otro divino como creador y doble, es la prosa dedicada a Shakespeare, "Everything and nothing". En este texto se adivina una y otra vez la premisa sobre la cual se ha trabajado en este análisis acerca de la identidad, como lo refleja la siguiente cita que indica el sentir del escritor: "Instintivamente, ya se había adiestrado en el hábito de simular que era alguien, para que no se descubriera su condición de nadie" (Borges, 2005b, p. 192). Sin embargo, como es común en la literatura borgesiana, lo verdaderamente 
impresionante llega hacia el final, en el que el autor inglés descubre el vacío que caracteriza a su propio creador:

La historia agrega que, antes o después de morir, se supo frente a Dios y le dijo: 'Yo, que tantos hombres he sido en vano, quiero ser uno y yo'. La voz de Dios le contestó desde un torbellino: 'Yo tampoco soy; yo soñé el mundo como tú soñaste tu obra, mi Shakespeare, y entre las formas de mi sueño estabas tú, que como yo eres muchos y nadie' (Borges, 2005b, p. 193 ${ }^{[12]}$.

Así, a la manera panteísta de "El inmortal”"13], la conclusión inmediata que surge de la presencia del doble en la literatura de Borges es que, ser muchos implica, necesariamente, ser nadie; en otras palabras, que exista un segundo yo, o un tercero (incluso si éste es Dios), constata la falta de identidad que el psicoanálisis ha señalado como inseparable del género humano: “...(la aparición del Otro) no sería más que el reconocimiento de la propia indigencia, del vacío que experimenta el ser en el fondo de sí mismo" (Bargalló, 1994, p. 11).

En ese sentido, se constata también la premisa antes revisada según la cual el Otro se encuentra, como el sujeto, barrado. Los creadores de los textos revisados, aun cuando poseen la facultad de dar vida, carecen de identidad y parece que también los caracteriza un vacío en su ser. De allí que, quizá, lo ominoso de su presencia tenga que ver con esta vacuidad. El sujeto, en su constitución, se va haciendo de un yo que no es más que una ilusión de identidad. Pero esta ilusión también alcanza al lugar desde el que se ha constituido, el Otro, en tanto éste se encuentra barrado. ¿Qué le queda al sujeto entonces sino la profunda angustia de saberse nadie? El doble, entonces, puede ser el doloroso recuerdo de dicha revelación.

\section{Conclusión}

Hay elementos particulares vinculados con el doble que cuestionan el estatuto de la identidad. En particular, los espejos, el Otro y lo ominoso, son los que se han explorado, de manera que también se ha podido vislumbrar las relaciones que éstos establecen entre sí.

En primer lugar, el espejo, motivo tan recurrente en la obra del argentino, es fundamental en el estadio que lleva su nombre para construir y, al mismo tiempo, interrogar al yo, dada la distancia que existe entre la imagen y el sujeto. Esta distancia, a su vez, parece indicar la separación de determinados personajes literarios con respecto a su doble acechante, mismo que no hace sino duplicar, a su vez, sus grietas y carencias. La alteridad refleja el vacío.

Más aún, esto ocurre también con la entidad que recibe el nombre de Otro desde el psicoanálisis y que en los escritos de Borges tiende a manifestarse en las figuras del creador y de Dios. De este modo, duplicando lo que sucede con los sujetos (los magos, los rabinos, Shakespeare o los teólogos), a la divinidad también le está negado el ser: no es nadie ${ }^{[14]}$. En términos de Rodríguez Monegal: 
En su mitología personal [la de Borges] no son sólo los hombres los que han sido soñados por Dios, sino Dios mismo, padre de todos los hombres, es tal vez fruto de un sueño. Pero el sueño, como el Golem, como el espejo, como la copulación, es también un simulacro (Rodríguez, 1984, p. 117).

En tercer lugar, está el fenómeno de lo unheimlich. Freud llamó "ominoso" al sentimiento de angustia frente a fenómenos como el doble o la experiencia de constricción, desvalimiento y subordinación ante el Otro. Empero, conforme a lo anterior, más ominosa podría resultar la consciencia terrible de su vacuidad, de la nada que está detrás de su resplandor ${ }^{[15]}$.

La identidad es, entonces, imposible tanto en la literatura borgeana como en la teoría psicoanalítica. Ambas perspectivas confluyen no sólo en esta premisa, sino en la manera en que el recurso del doble manifiesta una serie de elementos para confirmarla, tal y como se ha revisado a lo largo de este documento. Lo anterior, vale decirlo, no excluye otras tantas convergencias que puedan apuntar hacia la misma conclusión, en tanto la experiencia de leer a Borges sigue interrogando lo más profundo de la subjetividad humana.

\section{Referencias}

Bargalló, J. (1994). Hacia una tipología del doble: el doble por fusión, por fisión y por metamorfosis. En J. Bargalló (Ed.), Identidad y alteridad: aproximación al tema del doble (pp. 11-26). Ediciones Alfar.

Barrenechea, A. (1984). La expresión de la irrealidad en la obra de Borges. Centro Editor de América Latina.

Borges, J. L. (2005a). Obras Completas 1923-1949 (OCI) (Vol. I). Emecé Editores.

Borges, J. L. (2005b). Obras Completas 1952-1972 (OCII) (Vol. II). Emecé Editores.

Borges, J. L. (2005c). Obras Completas 1975-1985 (OCIII) (Vol. III). Emecé Editores.

Braunstein, N. (2008). Memoria y espanto o el recuerdo de infancia. Siglo XXI de España Editores.

Freud, S. (1915 [2010]). Lo inconsciente. En Obras Completas 1914-1916(Vol. XIV). Amorrortu Editores.

Freud, S. (1919 [2010]). Lo ominoso. En Obras Completas 1917-1919 (Vol. XVII). Amorrortu Editores.

Freud, S. (1923 [2010]). El yo y el ello. En Obras Completas 1923-1925 (Vol. XIX). Amorrortu Editores.

Fuentes, C. (1999). Borges: la herida de Babel. En R. Olea (Ed.), Borges: desesperaciones aparentes y consuelos secretos (pp. 294-312). El Colegio de México.

Huici, A. (1994). Borges y nosotros. De la metafísica a la literatura. En J. Bargalló (Ed.), Identidad y alteridad: aproximación al tema del doble (pp. 251-262). Ediciones Alfar.

Huici, A. (1998). El mito clásico en la obra de Jorge Luis Borges. El laberinto. Ediciones Alfar. 
Lacan, J. (1955 [2006]). El seminario de Jacques Lacan, libro 2: el yo en la teoría de Freud y en la técnica psicoanalítica 1954-1955. Paidós.

Lacan, J. (1957 [2006]). El seminario de Jacques Lacan, libro 4: la relación de objeto 1956-1957. Paidós.

Lacan, J. (1973 [2006]). El seminario de Jacques Lacan, libro 20: aún 1972-1973. Paidós.

Lacan, J. (2009). Escritos. Siglo XXI de España Editores

Lobo, E. (2010). El fenómeno del doble y su relación con lo siniestro. NODVS, $30,1-13$.

Muñoz, P. (2013). Acerca del fenómeno del doble. Verba Volant. Revista de Filosofía y Psicoanálisis, 3(1), 83-96.

Rodríguez, E. (1984). Borges por él mismo. Laia.

Sarlo, B. (2007). Borges, un escritor en las orillas. Siglo XXI de España Editores.

Urbina, M. (2010). Borges, creador de Dios. La configuración de Dios como personaje en la narrativa borgeana. Ediciones Eón.

Woscoboinik, J. (1988). El secreto de Borges. Indagación psicoanalitica de su obra. Editorial Trieb.

\section{Notas}

1 Carlos Fuentes precisa que, en cuanto al aspecto fantástico de la obra borgeana, el del doble es, junto a la obra dentro de la obra, el viaje en el tiempo y la invasión de la realidad por el sueño, uno de los temas imprescindibles del argentino (Fuentes, 1999, p. 296).

2 Particularmente se hará una revisión de las primeras acepciones que Lacan le atribuye al Otro, que tienen que ver con el lenguaje y la constitución del sujeto, sin olvidar que más adelante en su obra también hay elaboraciones particulares acerca del Otro y el cuerpo, así como lo que se dio por llamar el Otro sexo (Lacan, 1973 [2006]).

3 No es casual que, en otros términos, Huici haya encontrado que la preocupación sobre "el otro" en Borges, encuentra su semilla en Edipo quien, "buscando a otro se encontró a sí mismo" (Huici, 1998, p. 23), lo cual es una reiteración del fuerte vínculo entre el doble y la identidad.

$4 \quad$ Véase el ya aludido trabajo que hizo Néstor Braunstein al rastrear los primeros recuerdos de varios escritores y su relación con la angustia y su posterior oficio literario (Braunstein, 2008). En el caso de Borges, previsiblemente, el recuerdo de un espejo tripartito es fundamental.

5 "En vano quiero distraerme del cuerpo/y del desvelo de un espejo incesante/ que lo prodiga y que lo acecha” (Borges, 2005b, p. 253).

6 Esto mismo sucede con el famoso poema "Al espejo", que abarca lo dicho hasta aquí. El texto reza:

Eres el otro yo de que habla el griego/y acechas desde siempre. En la tersura/ del agua incierta o del cristal que dura/me buscas y es inútil estar ciego. /El hecho de no verte y de saberte/te agrega horror [las cursivas son mías], cosa de magia que osas/multiplicar la cifra de las cosas/que somos y que abarcan nuestra suerte (Borges, 2005b, p. 545).

7 Sin intención de describirlo en estos términos, Sarlo expresa una idea similar, que no puede pasar desapercibida:

El ideologema de los dobles, a través de quienes se cumplen destinos repetidos infinitamente y desconocidos por ellos, desplaza la aventura del coraje a un espacio intranquilo donde los personajes repiten acciones sin saber que son impulsados por fuerzas muy diferentes de las que creen reconocer en sus actos [las cursivas son mías] (Sarlo, 2007, p. 136). 
$8 \quad$ Es imposible no mencionar la evidente relación entre estos dos conceptos de acuerdo con la teoría lacaniana, según la cual, el inconsciente es el discurso del Otro, lo cual viene a reforzar la idea expresada.

9 "Al otro, a Borges, es a quien le ocurren las cosas... Por lo demás, yo estoy destinado a perderme, definitivamente, y sólo algún instante de mí podrá sobrevivir en el otro. Poco a poco voy cediéndole todo" (Borges, 2005b, p. 197).

10 "Con alivio, con humillación, con terror, comprendió que él también era una apariencia, que otro estaba soñándolo” (Borges, 2005a, p. 487).

11 Que uno de esos dobles se trate de la divinidad es un accidente menor, como se percibe en el poema "De que nada se sabe": "Quizá el destino humano/de breves dichas y de largas penas/es instrumento de Otro. Lo ignoramos; /darle nombre de Dios no nos ayuda [las cursivas son mías]. /Vanos también son el temor, la duda/y la trunca plegaria que iniciamos" (Borges, 2005c, p. 112).

12 En el análisis de este texto, Urbina (2010) comenta las consecuencias de esta anagnórisis. Cuando Shakespeare se sabe idéntico a los demás, "esto le devuelve una imagen fantasmal de lo que considera su único parámetro posible de existencia: la individualidad. Pero al desaparecer este concepto, siente que se difumina también su condición de ente vital” (Urbina, 2010, p. 130).

13 "Nadie es alguien, un solo hombre inmortal es todos los hombres. Como Cornelio Agrippa, soy dios, soy héroe, soy filósofo, soy demonio y soy mundo, lo cual es una fatigosa manera de decir que no soy" (Borges, 2005a, p. 579).

14 En términos lacanianos, esto podría entenderse como el principio según el cual no hay Otro del Otro.

15 En "El tintorero enmascarado Hákim de Merv" se describe una cosmogonía igual de inquietante: "En el principio de la cosmogonía de Hákim hay un Dios espectral. Esa divinidad carece majestuosamente de origen, así como de nombre y de cara" (Borges, 2005a, p. 346). 